\title{
Excellent Outcomes for All Students: A Whole System Approach to Widening Participation and Student Success in England
}

\author{
Liz Thomas \\ Edge Hill University, United Kingdom
}

\begin{abstract}
This article is about improving student retention and success to achieve excellent outcomes for all students. It draws on research undertaken by the author about student engagement and belonging; differential engagement and success, with a particular focus on commuter students, who experience intersectional disadvantage; and the development of a whole institution approach (WIA) to widening participation and student success. The research has been undertaken in England, and is situated within this policy context, in particular two national policy tools: Access and Participation Plans (APP) and the Teaching Excellence and Student Outcomes Framework (TEF), which all higher education providers are required to engage with if they wish to charge fees above certain thresholds. The article demonstrates how in England both the policy framework and higher education institutions are working towards a system-wide approach to achieve excellent outcomes for all students, irrespective of their background or circumstances.
\end{abstract}

Keywords: Commuter students; retention; student engagement; widening participation.

\section{Introduction}

This article draws on a range of research projects the author has undertaken in England looking at student success in the context of widening participation (WP) and increased diversity. The research contributes understanding about student retention and success, differential outcomes for students who experience intersectional disadvantage, and a whole institution approach to improving student experiences and outcomes. The research is situated within the English policy context, being both informed by and informing national policy. Through this review it can be argued that England has made positive strides towards a whole system approach, aiming to ensure excellent outcomes for all students.

As a result of reading this article readers should have a better understanding of the policy context and the author's research about widening participation and student success in England. This should provide insights into student experiences, differential outcomes and the concept and implementation of a whole institution approach (WIA). It also demonstrates how the policy context works to shape the WP agenda, and influences institutional priorities and approaches, contributing to a system-wide approach oriented towards excellent outcomes for all students.

This work is licensed under a Creative Commons Attribution 4.0 International Licence. As an open access journal, articles are free to use with proper attribution. ISSN: 2205-0795 


\section{The Policy Context in England}

The United Kingdom (UK) has a longstanding commitment to diversifying student participation in higher education; although more recently this and related policy agendas have played out differently in each of the four UK nations (see for example Vossensteyn et al., 2015 and the Commission on Widening Access 2014 for an overview of the English and Scottish approaches respectively). In England the most recent phase began in the late 1990s; initially the focus was on widening access to higher education, but by the early 2000s the widening participation agenda had extended to consideration of the retention and completion of new student groups, as participation without qualification was viewed to be short-changing students. Since this time, concern about student success has grown as a result of the introduction of student fees and the abolition of maintenance grants; and this has been accompanied by an expanded appreciation of success, to move beyond just retention and completion, to consideration of differential attainment and graduate outcomes. The current focus, as is demonstrated below, is on excellent, or at least equivalent, outcomes for all students.

In 2013 the Higher Education Funding Council for England (HEFCE) identified four outcomes of higher education that could be measured for students: achieving a degree (retention and completion); achieving a first or upper-second class degree (attainment); achieving a degree and continuing to employment or further study; and achieving a degree and continuing to graduate employment (as opposed to any employment) or postgraduate study. Analysis of these outcomes by student equity characteristics demonstrated that students who were less likely to participate in higher education were also less likely to be successful against all of these measures (HEFCE, 2013). These insights have informed and heighted concern about differential outcomes for particular equity groups (see for example, Mountford-Zimdars et al. 2015), and ethnic minorities in particular (e.g. UUK/NUS 2019).

\section{Access and Participation Plans}

In 2018 the Office for Students (OfS) was formed, as the independent regulator of higher education in England, and replacing the Higher Education Funding Council for England and the Office for Fair Access. All higher education providers operating in England are required to register with the OfS, and there are various initial and ongoing conditions which must be met. One requirement for institutions that wish to charge fees above the basic amount is to have an Access and Participation Plan (APP). Access and Participation Plans set out how higher education providers will improve equality of opportunity for underrepresented groups to access, succeed in and progress from higher education. More specifically, these publicly available documents include: the provider's ambition for change; details of what the provider plans to do to achieve that change; targets that the provider has set; and investment that will be made to deliver the plan to meet the targets. (OfS, 2019). In the guidance for current plans, 2020/1 to 2024/5, there is strong emphasis on identifying differential outcomes in relation to participation, continuation/completion, attainment and graduate progression, and addressing these gaps through robust interventions:

A plan must include an analysis of the gaps between underrepresented groups and other student groups in absolute terms, and consider progress over time in closing those gaps where there is available data... The assessment of performance must cover all stages of the student lifecycle (access, student success, and progression to employment or further study). The analysis of student success must consider both non-continuation and attainment. Progression analysis must include both progression to employment/further study and progression to highly skilled employment.

As a minimum, a provider's assessment of performance must cover groups of students who share the following particular characteristics: Those living in areas of low higher education participation or from lower household income or socioeconomic status backgrounds; Black, Asian and minority ethnic students; mature students; disabled students [and] care leavers...

...Providers must clearly set out in their plan the strategic aims and objectives which reflect the areas for development identified in their assessment of performance. (OfS, 2019, p. 21-22).

Conditions of registration are that the APP must be approved by the OfS, the institution must take reasonable steps to adhere to the plan, which must be published, and institutions must produce an annual update. Furthermore, the plans are monitored by the OfS to ensure providers honour their commitments to students; the OfS can impose additional conditions of registration if they feel the targets or the plans are inappropriate or that insufficient progress is being made. These conditions identify minimum requirements that providers must meet to remain registered, and are the primary approach used in England to ensure all providers actively address student diversity and success. In addition to having an approved APP, the majority of higher 
education providers in England also have a Teaching Excellence and Student Outcomes Framework (TEF) award. TEF is an additional tool that reinforces expectations that students from equity groups should have a comparable experience in and outcomes from higher education.

\section{Teaching Excellence and Student Outcomes Framework (TEF)}

TEF is a government initiative designed to assess and enhance excellence in undergraduate teaching in universities and colleges across the UK, but it has been more widely adopted in England. It was launched in 2016, but the process was developmental and is still being reviewed (DfE 2019), with details for 2020 and beyond still rather sketchy (Kernohan, 2019). A TEF award is required for all higher education providers who wish to charge up to the highest maximum fee level (currently up to £9250 per year), hence the greater level of take up in England.

The TEF process utilises a number of metrics, and providers also submit a narrative explaining the data and presenting additional evidence, to demonstrate performance against a range of criteria relating to teaching quality, learning environment and student outcomes and learning gain. The metrics data is provided by the OfS, and includes data about students' satisfaction in relation to teaching, assessment and feedback and academic support collected via the National Student Survey; continuation rate data collected by the Higher Education Statistics Agency; and employment outcome measures (collected via the Destination of Leavers from Higher Education until 2018, and subsequently by the Graduate Outcomes survey). An important aspect of the TEF is the emphasis on positive outcomes for all students, and the metrics data is broken down in relation to particular underrepresented groups: age, disadvantage (low SES using a geographically based measure), ethnicity, disability and sex.

While there are many criticisms of the TEF process and its use of indicators that do not directly measure teaching quality and excellence (Gunn, 2018; Shattock, 2018), it does make an important contribution to equity, drawing attention to differences between student groups and effectively requiring institutions to look to improve the experience, continuation and outcomes of underrepresented student groups. Taken together, Access and Participation Plans and the Teaching Excellence and Student Outcomes Framework place the success of widening participation cohorts at the heart of institutional priorities, rather than on the margins, and create a system-wide framework for improving the outcomes of all students.

\section{Research to Improve Student Retention and Success}

\section{Student Integration, Engagement and Belonging}

Much of the literature on student retention and success is from the US, and the work of Vincent Tinto has been highly influential; his model first presented in 1975 and expanded in the 1993 version is widely used and highly respected (Kember, 1995). According to Tinto's theory, 'student departure' arises from a longitudinal process of interactions between an individual with given attributes, skills, financial resources, prior educational experiences and dispositions (intentions and commitments), and their integration with the academic and social systems of the institution (Tinto, 1993). Students entry characteristics affect the extent of their social and academic interaction within a learning institution, and the extent of their integration, which in turn impacts on their goals and institutional commitment - and retention. In order to continue in HE, students need to be integrated into both the academic and social systems of an institution. This includes participation in formal academic activities, and social interaction with peers and academic staff, including taking part in extra and co-curricular activities (Kuh et al., 2010).

My own research in the UK builds on Tinto's work and applies it to the UK context (Thomas 2012; Thomas et al 2017). The first What Works? Student Retention and Success programme (2008-12, reported in Thomas, 2012) explored effective approaches to improve student retention and success through seven projects involving twenty-two higher education institutions. Mixed methods were used to explore interventions, combining qualitative and survey research about student experiences with institutional data about retention and progression. The findings showed the importance of student engagement and belonging, but did not prescribe specific interventions. In summary, Thomas (2012) concluded that:

At the heart of successful retention and success is a strong sense of belonging in HE for all students. This is most effectively nurtured through mainstream activities that all students participate in... The academic sphere is the most important site for nurturing participation of the type which engenders a sense of belonging (p. 6). 
Student engagement and belonging are closely related concepts, as engagement generates belonging. Engagement is now a widely used term in the higher education (HE) sector, but it is a slippery concept (Gibbs, 2014; Trowler, 2010), often without a shared definition even within a single institution or department (Thomas, 2017). Broadly, engagement points to students playing a more active role in their learning and wider student experience (e.g. Coates, 2005). Belonging refers to the relational and emotional aspects of students' student experience (Thomas, 2012; Vallerand, 1997), and the research discovered that effective interventions develop students' sense of belonging through encouraging supportive relationships with peers; fostering meaningful interaction between staff and students; developing students' capacity (knowledge, skills, confidence and identity) to be successful HE learners; and an HE experience which is relevant to their current interests and future goals (Thomas, 2012). The evidence from the What Works? programme identifies the importance of students having a strong sense of belonging in $\mathrm{HE}$, which is the result of engagement, and this is most effectively nurtured through mainstream activities with an overt academic purpose that all students participate in (Thomas, 2012, p. 12).

These findings indicate that responsibility for improving retention and success does not just lie with students, but institutions and their teaching and professional staff have an obligation to provide the necessary conditions, opportunities and expectations for such engagement to occur (Coates, 2005; Thomas, 2012; Tinto, 2009). Thus, institutions can create engaging opportunities (Reason et al., 2005, 2007; Thomas, 2012). Thomas found that some specific learning and teaching interventions improved retention rates by up to ten percentage points (Thomas, 2012, see also Braxton et al., 2000; Nevill \& Rhodes, 2004).

\section{Differential Engagement and Belonging}

In the second phase of the What Works? Student Retention and Success programme (Thomas et al 2017) thirteen universities implemented and evaluated changes to both academic courses and the institutional context to improve student engagement and belonging, and the process and impact were researched using a mixed methods action research model (see Thomas underreview). One of the findings what that some groups of students find it more challenging to engage than others, a slightly revised set of characteristics of effective interventions, and insights into the process of change. A survey of engagement and belonging was developed (Yorke, 2016) and administered across students in participating academic programmes seven times over the three-year period of implementation. The analysis across the institutions found that male students tend to be less engaged than their female peers; older students (aged 20 and above) tend to be more engaged than younger students; White British students tend to exhibit a stronger sense of 'belongingness' than other respondents; and students who are not relatively disadvantaged by their circumstances (including travelling to study, care responsibilities and limited access to a quiet place where they can do academic work) tend to exhibit a stronger sense of 'belongingness' than those whose circumstances are more disadvantageous. Further analysis reveals that lengthy travel time to and from the university and having difficulty in finding a quiet space in which to do academic study, especially taken together, have an adverse effect on students belonging within higher education.

\section{Commuter Students}

Research that has taken place after the conclusion of the What Works? programme has focused on commuter students, i.e. those students who remain in the family home and are not studying a distance learning programme or similar, but rather travel to their place of study. While the concept of a commuter student is still poorly defined in England (Thomas \& Jones, 2017), analysis of data national data on full-time, young students from the UK attending university in 2009-10 and 2014-15 finds that students from the lower social classes, students from state schools and students from certain ethnic minorities are more likely to commute (Donnelly \& Gamsu, 2018). More specifically: students in the lowest social class group are more than three times more likely to commute from home than those from the highest group (44.9\% compared with $13.1 \%$ ); state school students are 2.6 times more likely to stay at home and study locally than their privately educated counterparts, even after controlling for other factors including class, location and attainment. British Pakistani and British Bangladeshi students are over six times more likely than White students to stay living at home while studying at local higher education providers. In summary Donnelly and Gamsu (2018) state: "leaving home and attending a distant university is too often the preserve of white, middle class, privately educated young people" (p. 4). Maguire and Morris (2018) found that commuter students are: "more likely to be the first generation in their families to enter higher education, have a lower income, be mature and be from an ethnic minority background" (p. 7). Thus, it can be concluded that commuter students embrace a wide range of non-traditional student characteristics, and many such students experience intersectional disadvantage, which is compounding and worsens the outcome (Crenshaw, 1991). 
In terms of the outcomes, the evidence from a number of sources finds that in England, commuter students as a group have poorer outcomes from higher education than residential students, i.e. students who relocate to live at or near their place of study; this point is made by Maguire and Morris (2018, p. 7), and other studies contribute more specific evidence. Students who live at home have lower rates of continuation (London Higher, 2019; Social Market Foundation, 2017). Students who live at home are less likely to get a $2: 1$ or $1^{\text {st }}$ class degree, despite reporting the same level of skill development (Neves \& Hillman, 2016). A study focusing on medical students found that living more than 30 minutes from campus is correlated with greater academic failure (Dante et al., 2013). Comparative analysis of employment outcomes between students who lived at home and students who lived away from home, found that students who lives at home were less likely to be employed in a graduate job (Artess et al., 2014). Furthermore, students who live further and/or live at home perceive lower value for money from their higher education experience, and are less likely to choose the same course and institution again (Neves \& Hillman, 2018, p. 28).

Qualitative research was undertaken with commuter students as part of a project on commuter student engagement (Thomas \& Jones, 2017). Sixty semi-structured interviews were undertaken with students who self-identified themselves as commuters, nine higher education institutions, representing a range of institutional types and geographical locations. Students were paid a small flat rate of $£ 9.00$ for participating in the interviews. The interviews were digitally recorded, transcribed, and analysed thematically by the research team. The focus of the interviews was on engagement in different parts of the institution and/or for different purposes. Academic engagement relates to students' engagement in their own learning; engagement for enhancement relates to students' engagement in co-curricular and enhancement activities, including representation, curriculum design and leadership roles, which contribute to personal and professional development; and social engagement relates to participation in both formal and informal sport, social and leisure activities with HE peers, including unstructured socialising.

A summary of the findings is presented here; the full findings are available in Thomas and Jones (2017). The findings are presented in relation to four key themes: the experience of commuting to study; academic engagement; engagement in enhancement activities; and social engagement.

\section{Commuting to Study:}

(T)here are days when you don't feel like you want to be on a busy bus, packed in for about an hour trying to get to one place to only have to be there for an hour, then getting back on a busy bus. It takes a lot of energy out of you, energy which you could probably use for studying if you weren't commuting. (Lily)

The experience of commuting is generally experienced negatively. Students found commuting time consuming, tiring, expensive and stressful. Furthermore, students reported having little or no idea before deciding to commute to their course of study how much time they would spend travelling or how much it would cost.

Once at their place of study, commuter students found other practical challenges relating to their lack of a physical space on campus to store belongings and spend time. Students were forced to carry their possessions with them, which is not only inconvenient and may reduce the activities they engage in on campus, but also marked them out as different. In addition, commuter students lacked informal space to spend time with did not require them to either be studying or spending money (e.g. cafes). These practical challenges differentiated commuter students, and contribute to a perception that they were not recognised, and arguably do not belong within the institution.

\section{Academic Engagement:}

I could've had plenty of friends, but I, kind of, kept myself to myself because I didn't want it to affect my education. Education is number one for me. So I just do my work, go home, and party a lot at home, with plenty of friends I could hang around with. So I try to keep myself not distracted in uni (Ella).

The majority of students who participated in the study prioritised their academic engagement, at the expense of other forms of engagement. They made an effort to attend taught sessions and usually managed to accommodate the demand of course-related group work. Students did however discuss evaluating the value of attendance in terms of time and money, and their decisions to attend were informed by both the number of contact hours and the perceived quality of the sessions. 
Commuter students identified a range of ways in which their academic experience was marred by being a commuter, and the associated attitudes and behaviour of staff. For example, students discussed not entering lectures if they had been delayed and arrived late, for fear of being humiliated by the teaching staff, and some talked of not being allowed to enter. Students sense that staff have an expectation that all students should live on or near to campus, and this is reflected in institutional processes such as the reliance on face-to-face teaching, a preference for in person meetings, requirements to submit assessed work in person, late notice of the cancellation of teaching sessions, docking marks in routine assessments for late arrival, and the allocation of professional placements which takes no account of location. These practices denote an institutional culture that is not inclusive of commuter students.

\title{
Engagement in Enhancement and Social Activities:
}

\begin{abstract}
In terms of transportation, it's expensive for a commuter student to be constantly coming to the university every time, compared to a group of people who could easily go to the same place together. If we said to meet up in a gathering place, where we can talk, be together and hang out, it's harder for commuting students to come. If there's no real purpose in the journey and you sacrifice socialising. It's more tiring to continuously go through journeys for frequent meet ups and group discussions (Jaban).
\end{abstract}

Commuter students tend to depriotise engagement in both enhancement and social activities. This is due to the timing of activities, usually in the evening, and the limitations of public transport and associated security concerns. This de-prioritising reflects the lack of value attached to these activities by commuter student, who do not generally recognise the contribution of enhancement activities to graduate employment outcomes or of social engagement to their learning (Stuart et al., 2011). Rather they tended to rush off at the end of taught sessions in order to travel home. It also becomes a viscous circle, in that if you have fewer friends, the opportunities for engagement in social and extra-curricular activities diminish.

\section{Implications for Institutions: A Whole Institution Approach (WIA)}

The research with commuter students demonstrates that they have lower engagement than other groups of students, and this is likely to contribute to their lower sense of belonging and poorer outcomes in terms of retention, attainment, and progression into graduate employment. Higher education institutions should, for either self-serving or moral reasons, take greater responsibility, and improve the engagement and belonging of students from non-traditional groups. The curriculum can be used to address many of these engagement challenges (Thomas 2012; Thomas et al., 2017), because it is within institutional control and the one thing that all students have in common (Kift et al., 2010). Curriculum organisation, contents design and pedagogy can support students to use their time more wisely by reducing the need for unnecessary travel, increasingly the value of time spent on campus, and facilitating wider student engagement (Thomas, 2018). This needs to be underpinned by the development of staff understanding of, and attitudes towards, non-traditional students, and the development amongst these student groups an appreciation of the contribution of engagement in the wider student experience to academic success and progression to graduate employment. WIA can also be employed to help maximise the opportunities for engagement and success by students from non-traditional groups.

A study commissioned in 2017 by the Office for Fair Access was undertaken to generate evidence and guidance to assist English HEIs to further develop and evaluate their WIA to widening participation (Thomas, 2017a). A case study methodology was used, based on delivering a workshop with a cross-section of staff from five universities and colleges. Evidence was collected through discussions, material produced collaboratively by groups of staff and through individual staff responses recorded during the workshop in a workbook.

Three core and essential features of a whole institution approach were identified, which are adopting a 'whole lifecycle' approach, i.e. not just focusing on who gets into an institution, but also looking at their experiences and outcomes in higher education and beyond; having the involvement of staff from departments, services and units from across the institution in widening participation, and not just 'professional widening participation' staff; and having a clear and explicit institutional commitment to widening participation, including defining target groups and expected outcomes. A range of additional features were exhibited by the case study institutions, and these provided examples of ways in which the whole institution approach could be extended (Thomas, 2017).

While most English institutions work across the student lifecycle, this has often been led by individual enthusiasts or champions, and this in turn has developed into 'pockets of excellence' in specific parts of most institutions. The challenge many institutions 
are faced with is alignment of policies and practices across the institution to provide consistency so that an inclusive approach benefits all students, irrespective of where they are located within the institution. An inclusive approach:

\begin{abstract}
... necessitates a shift away from supporting specific student groups through a discrete set of policies or time-bound interventions, towards equity considerations being embedded within all functions of the institution and treated as an ongoing process of quality enhancement. Making a shift of such magnitude requires cultural and systemic change at both the policy and practice levels (May \& Bridger, 2010, p. 6).
\end{abstract}

Arguably, an inclusive approach should extend not just across the student lifecycle (from pre-entry to progression beyond the institution), which can be understood as vertical alignment, but throughout students' daily lived experiences, incorporating their academic life, and also their personal and social well-being and their professional development (horizontal alignment). Felten et al (2016) argue that HE staff tend to prioritised vertical alignment across time, whereas students (also) value and benefit from horizonal alignment, which reflects their daily lived experiences. Alignment involves:

\begin{abstract}
... matching resources, policies, and practices with the institution's educational purposes and student characteristics through forging educational partnerships within and among traditional organisational boundaries, especially faculty, academic affairs, and student affairs units (Kuh et al.,, 2010, cited in Felten et al., 2016, p. 92).
\end{abstract}

In England, the focus of widening participation policy, funding and practice from the mid-1990s onwards was on access, (achieved through outreach programmes) and subsequently the provision of additional financial support to offset the introduction of tuition fees. At the start of the twenty first century, widening participation was extended across the student lifecycle to incorporate student success, but financial support generally continued to operate in parallel to this, rather than being integrated. The aim of a whole institution approach is to achieve alignment and therefore consistency across the lifecycle and lived experience, for all students, because, as was demonstrated through the example of commuter students, many nontraditional groups will de-prioritise engagement in enhancement and social activities, which has negative consequences for their attainment and progression into graduate employment. Cross-institutional partnerships and involving all staff are challenging to achieve.

Drawing on research about developing an inclusive approach, it is clear that both the culture and the structure of the institution need to be addressed, and this can be understood as what Kift (2009) describes as a 'top-down, bottom-up' approach. Similarly, May and Bridger (2010) found that it was necessary to undertake changes at both the institutional and the individual levels to engage staff and bring about change:

\footnotetext{
... organisational change required to bring about inclusive policy and practice fell into two broad categories: institutional-level change: targeting institutional policy, strategy, structures, systems, processes and/or environmental factors, whether centrally or within departments/faculties; individual-level change: targeting individuals' attitudes, awareness, knowledge, understanding, perceptions and assumptions, as well as practice (p. 36).
}

Culture refers to the values, attitudes and practices of the staff (and students) within the higher education providers (HEP), while structure refers to the institutional policies, processes and organisation (e.g. of financial and human resources) of the HEP and its sub-units. The interplay of culture and structure should enable people to be sufficiently well informed and have the capacity and commitment to implement inclusive practices, while the structure both facilitates and ensures this, and provides co-ordination across the institution, promoting integration and consistency of outcomes - and avoiding duplication, fragmentation and gaps in provision. Thus, the essential strategies for implementing a whole institution approach, which ensures both the structure and the cultural context is facilitative of widening participation and diversity can be understood to require:

- Vertical alignment: A whole lifecycle approach to WP is adopted.

- Horizontal alignment: Staff from departments, services and units from across the institution are involved in WP (i.e. not just 'professional WP' staff).

- Institutional commitment and leadership: A clear and explicit institutional commitment to WP, defining target groups and expected outcomes as appropriate.

- Pragmatic approach to change: A top-down, bottom-up approach is adopted, developing a culture and structure that promote and supports inclusivity and consistency. This incorporates: 
- Staff capacity and engagement: The values, attitudes and practices of the staff and students within the HEP promote and support WP.

- Institutional structures facilitate ownership and communication: The institutional policies, processes and organisation (e.g. of financial and human resources) of the HEP and its sub-units promote and support WP across the institution.

- Evidence informed and accountability: Data and evidence is used to understand the issues, ensure staff accountability, monitor student experience and outcomes, inform strategic and operational decision-making, and evaluate the process and impact.

Developing an institutional structure that promotes WP involves ensuring policies, processes and organisation take account of WP and diversity (structure as espoused); considering the extent to which structure are enacted (i.e. they are implemented and move beyond paper-based aspirations or statements); and assessing the impact or effect of the structure on WP/diverse students (informed by Evans et al., 1999). Culture refers to the values, attitudes and practices of the staff (and students). Developing a 'WP friendly' or inclusive culture can be understood to involve: raising people's awareness and understanding of the issues; developing people's skills and capacity to deliver inclusive practice; changing the individual practice (which can be encouraged or required by institutional structures); and demonstrating the impact of people's practice on the experiences or outcomes of students from target groups.

\section{Conclusions}

England provides an interesting case study in how the widening participation agenda has matured (Kift et al., 2010), and arguably there is now a whole system approach oriented towards excellent outcomes for all students. Figure 1, presents a summary of the English WP maturity model. The policy context in England has facilitated and led the sector, at least to some extent, towards a more inclusive approach to widening participation which values the success of all students and recognises the importance of institutional change. The two new policy tools employed by the OfS require institutions to work towards excellent, or at least equivalent, outcomes for all students. This work has been strongly informed by data analysis, practitioner evaluation and academic research.

\section{Figure 1}

Widening Participation Maturity Model

First generation: Widening access and retention

Individual champions undertaking projects to help non-traditoinal students get in and stay in an unreformed $\mathrm{HE}$ institution/system (fixing up students)

Second generation: Academic success across the lifecycle

Pockets of excellence as some teams work together across the student lifecycle to improve academic engagement, belonging and success through curriculum change

A whole institution approach as all staff work across the lifecycle and student experience, changing the institution's culture and structure 
Overtime there has been increased awareness of the disparities within and beyond higher education, rather than just with who is admitted to the academy. This realisation has been partly due to success in widening access, but also to greater analysis of student experiences and outcomes by specific equity characteristics. In England there is a vibrant and growing research and evaluation focus on widening participation that has critiqued and informed this work, and there is now significant recognition of the need for transformed institutions that are genuinely more inclusive, hence the development of the third generation of widening participation. This requires fundamental institutional change, and involves all staff and students if the aspiration of achieving excellence for all, or at least equivalent outcomes for students from disadvantaged backgrounds is to be achieved.

\section{References}

Artess, J., McCulloch, A., Mok, P. (2014). Learning from Futuretrack: Studying and living at home. https://hecsu.ac.uk/assets/assets/documents/Futuretrack_BIS_Learning_from_futuretrack_studying_and_living_at_home. pdf

Braxton, J.M., Milem, J.F., \& Sulivan, A.S. (2000). The influences of active learning on the college student departure process: Toward a revision of Tinto's theory. The Journal of Higher Education. 71(5), 569-590. https://doi.org/10.1080/00221546.2000.11778853

Coates, H. (2005). The value of student engagement for higher education quality assurance. Quality in Higher Education, 11(1), 25-36. https://doi.org/10.1080/13538320500074915

Commission on Widening Access (2016). A blueprint for fairness. The final report of the Commission on Widening Access. https://www.gov.scot/publications/blueprint-fairness-final-report-commission-widening-access/

Crenshaw, K. (1991). Mapping the margins: Intersectionality, identity politics, and violence against women of color. Stanford Law Review 43(6), 1241-1299. doi:10.2307/1229039

Dante, A., Fabris, S., \& Palese, A. (2013). Time-to-event analysis of individual variables associated with nursing students' academic failure: A longitudinal study. Advances in Health Sciences Education: Theory and Practice, 18(5), 1047-1056. https://doi.org/10.1007/s10459-013-9448-6

Donnelly, M. \& Gamsu, S. (2018). Home and Away - social, ethnic and spatial inequalities in student mobility. https://www.suttontrust.com/wp-content/uploads/2018/02/Home_and_away_FINAL.pdf.

Evans, K. Behrens, M., Hoffmannn, B., Saxby-Smith, S. and Rudd, P. (1999). Comparative successes or failures? Some methodological issues in conducting international comparative research in post-secondary education. [Paper presentation] British Educational Research Association Annual Conference, University of Sussex, United Kingdom.

Felten, P., Gardner, J., Schroeder, C., Lambert, L. and Barefoot, B. (2016). The Undergraduate Experience. Focusing institutions on what matters most. Jossey-Bass

Gibbs, G. (2014, May 1). Student engagement, the latest buzzword. Times Higher Education, https://www.timeshighereducation.com/news/student-engagement-the-latest-buzzword/2012947.article

Gunn, A. (2018). Metrics and methodologies for measuring teaching quality in higher education: Developing the Teaching Excellence Framework (TEF). Educational Review, 70(1), 129-148. https://doi.org/10.1080/00131911.2017.1410106

Higher Education Funding Council for England [HEFCE] (2013). Higher education and beyond. Outcomes from full-time first degree study. https://dera.ioe.ac.uk/17941/1/Higher\%20education\%20and\%20beyond $\% 20$ Outcomes $\% 20$ from $\% 20$ fulltime\%20first\%20degree\%20study.pdf

Kember, D. (1995). Open learning courses for adults: A model of student progress. Educational Technology Publications Kernohan, D. (2019, September 17) What the (extra) TEF? Wonkhe https://wonkhe.com/blogs/what-the-extra-tef/

Kift, S. M. (2009). Articulating a transition pedagogy to scaffold and to enhance the first year student learning experience in Australian higher education. http://transitionpedagogy.com/

Kift, S., Nelson, K., \& Clarke, J. (2010). Transition pedagogy: A third generation approach to FYE: a case study of policy and practice for the higher education sector. The International Journal of the First Year in Higher Education, 1(1), 120. https://doi.org/10.5204/intjfyhe.v1i1.13 
Kuh, G., Kinzie, J., Schuh, J., Whitt, E., \& Associates (2010). Student success in college: Creating conditions that matter. Jossey-Bass

London Higher (2019). London higher factsheet 2019. Students in higher education 2017/18. https://www.londonhigher.ac.uk/wp-content/uploads/2019/07/LdnHigher_HESAStudents2019.pdf

Maguire, D., \& Morris, D. (2018). Homeward Bound: Defining, understanding and aiding 'commuter students'. Higher Education Policy Institute.

May, H., \& Bridger, K. (2010). Developing and embedding inclusive policy and practice in higher education. https://www.advance-he.ac.uk/knowledge-hub/developing-and-embedding-inclusive-policy-and-practice-highereducation

Mountford-Zimdars, A., Sabri, D., Moore, J., Sanders, J., Jones, S., \& Higham, L. (2015). Causes of differences in student outcomes. https://dera.ioe.ac.uk/23653/1/HEFCE2015_diffout.pdf

Neves, J., \& Hillman, N. (2018). 2018 Student academic experience survey. https://www.hepi.ac.uk/2018/06/07/2018student-academic-experience-survey/

Nevill, A., \& Rhodes, C. (2004). Academic and social integration in higher education: A survey of satisfaction and dissatisfaction within a first year education studies cohort at a new university. Journal of Further and Higher Education. 28(2). 179-193. https://doi.org/10.1080/0309877042000206741

Office for Students [OfS] (2019). Regulatory Notice 1. Access and participation plan guidance. https://www.officeforstudents.org.uk/media/0bcce522-df4b-4517-a4fd-101c2468444a/regulatory-notice-1-access-andparticipation-plan-guidance.pdf

Reason, R. D., Terenzini, P. T. \& Domingo, R. J. (2005). First things first: Developing academic competence in the first year of college. Research in Higher Education, 47(2), 149-175. https://doi.org/10.1007/s11162-005-8884-4

Reason, R. D., Terenzini, P. T., \& Domingo, R. J. (2007). Developing social and personal competence in the first year of college. The Review of Higher Education, 30(3), 271-299. https://doi.org/10.1353/rhe.2007.0012

Shattock, M. (2018). Better informing the market? The Teaching Excellence Framework (TEF). International Higher Education, 92. 21-22. https://doi.org/10.6017/ihe.2018.92.10283

Social Market Foundation (2017). On course for success? Student retention at university. UPP Foundation http://www.smf.co.uk/wp-content/uploads/2017/07/UPP-final-report.pdf.

Stuart, M., Lido, C., Morgan, J., Solomon, L., \& May, S. (2011). The impact of engagement with extracurricular activities on the student experience and graduate outcomes for widening participation populations. Active Learning in Higher Education 12(3), 203-215. https://doi.org/10.1177\%2F1469787411415081

Thomas, L. (2012). Building student engagement and belonging in Higher Education at a time of change: Final report from the What Works? Student Retention \& Success programme.

https://www.heacademy.ac.uk/system/files/what_works_final_report_0.pdf

Thomas, L. (2017). Evaluating student engagement activity: Report, framework and guidance. https://www.thescholarshipframework.co.uk/resources/evaluating-student-engagement-activity-report-framework-andguidance

Thomas, L. (2017a). Understanding a whole institution approach to widening participation. Office for Fair Access. https://www.voced.edu.au/content/ngv\%3A78834

Thomas, L. (2018, June 20-22). 'I use my time more wisely...' The implications for learning and teaching in higher education of more 'commuter students'. [Paper presentation] $4^{\text {th }}$ International Conference on Higher Education Advances (HEAd' 18), Valencia, Spain. http://headconf.org/head18/wp-content/uploads/pdfs/8165.pdf

Thomas, L. (under review). Using logic chain and theory of change tools to evaluate widening participation: Learning from the What works? Student retention and success programme.

Thomas, L., Hill, M., O’ Mahony, J., \& Yorke, M. (2017). Supporting student success: Strategies for institutional change. What Works? Student Retention \& Success programme final report. https://www.advance-he.ac.uk/knowledgehub/supporting-student-success-strategies-institutional-change

Thomas, L., \& Jones, R. (2017). Student Engagement in the context of Commuter Students. https://www.lizthomasassociates.co.uk/projects/2018/Commuter\%20student\%20engagement.pdf

Tinto, V. (1975). Dropout from higher education: A theoretical synthesis of recent research. Review of Educational Research. 45(1), 89-125. https://doi.org/10.3102\%2F00346543045001089

Tinto, V. (1993). Leaving college: Rethinking the causes and cures of student attrition. University of Chicago Press.

Tinto, V. (2009, February). Taking student retention seriously: Rethinking the first year of university. [Paper presentation] FYE Curriculum Design Symposium 2009, Queensland University of Technology, Brisbane, Australia.

Trowler, V. (2010). Student engagement literature review. Higher Education Academy. https://www.heacademy.ac.uk/system/files/StudentEngagementLiteratureReview_1.pdf

Vallerand, R.J. (1997). Toward a hierarchical model of intrinsic and extrinsic motivation. In M.P Zanna (ed.) Advances in experimental social psychology (pp. 271-360). Academic Press. 
Vossensteyn, J., Stensaker, B., Kottmann, A., Hovdhaugen, E., Jongbloed, B., Wollscheid, ... Unger, M. (2015). Drop-out and completion in higher education in Europe. A report prepared by CHEPS and NIFU. https://supporthere.org/sites/default/files/dropout-completion-he_en.pdf

Yorke, M. (2016). The development and initial use of a survey of student 'belongingness', engagement and self-confidence in UK higher education. Assessment and Evaluation in Higher Education, 41(1), 154-166.

https://doi.org/10.1080/02602938.2014.990415

\section{Please cite this article as:}

Thomas, L. (2020). Excellent outcomes for all students: A whole system approach to widening participation and student success in England. Student Success, 11(1), 1-11. https://doi.org/10.5204/ssj.v11i1.1455

Student Success: A journal exploring the experiences of students in tertiary education

(c) (1) This work is licensed under a Creative Commons Attribution 4.0 International Licence. As an open access journal, articles are free to use with proper attribution. ISSN: 2205-0795 